\title{
Predictors of Plasma Concentrations of DDE and PCBs in a Group of U.S. Women.
}

\section{Citation}

Laden, F., L. M. Neas, D. Spiegelman, S. E. Hankinson, W. C. Willett, K. Ireland, M. S. Wolff, and D. J. Hunter. 1999. Predictors of plasma concentrations of DDE and PCBs in a group of U.S. women. Environmental Health Perspectives 107(1): 75-81.

\section{Published Version}

doi:10.1289/ehp.9910775

\section{Permanent link}

http://nrs.harvard.edu/urn-3:HUL.InstRepos:4889499

\section{Terms of Use}

This article was downloaded from Harvard University's DASH repository, and is made available under the terms and conditions applicable to Other Posted Material, as set forth at http:// nrs.harvard.edu/urn-3:HUL.InstRepos:dash.current.terms-of-use\#LAA

\section{Share Your Story}

The Harvard community has made this article openly available.

Please share how this access benefits you. Submit a story.

\section{Accessibility}




\title{
Predictors of Plasma Concentrations of DDE and PCBs in a Group of U.S. Women
}

\author{
Francine Laden, 1,2 Lucas M. Neas, 1,2,3 Donna Spiegelman, 2,4 Susan E. Hankinson, 1,2 Walter C. Willett, 1,2,5,6 \\ Karen Ireland, ' Mary S. Wolff,' and David J. Hunter ${ }^{1,2,6}$
}

'Channing Laboratory, Department of Medicine, Brigham and Women's Hospital and Harvard Medical School, Boston, MA 02115 USA; ${ }^{2}$ Department of Epidemiology; ${ }^{3}$ Department of Environmental Health; ${ }^{4}$ Department of Biostatistics; ${ }^{5}$ Department of Nutrition, Harvard School of Public Health, Boston MA 02115 USA; ${ }^{6}$ Harvard Center for Cancer Prevention, Boston MA 02115 USA; ${ }^{7}$ Department of Community Medicine, Environmental and Occupational Medicine, Mount Sinai School of Medicine, New York, NY 10029 USA

\begin{abstract}
We evaluated predictors of plasma concentrations of dichlorodiphenyldichloroethylene (DDE), a metabolite of dichlorodiphenyltrichloroethane (DDT), and polychlorinated biphenyls (PCBs) in a group of 240 women, controls from a breast cancer case-control study nested in the Nurses' Health Study. We considered personal attributes such as age, serum cholesterol, region of residence, adiposity, lactation, and dietary intake. DDE levels increased $0.17 \mathrm{ppb} /$ year of age $(p=$ $0.0003)$, and PCBs increased $0.08 \mathrm{ppb}(p=0.0001)$. DDE and PCBs increased $0.20(p=0.02)$ and $0.13 \mathrm{ppb}(p=0.001)$, respectively, per $10 \mathrm{mg} / \mathrm{dl}$ serum cholesterol. Women living in the western United States had higher levels of DDE (mean $=11.0 \mathrm{ppb} ; p=0.003$ ), and women in the Northeast and Midwest had higher levels of PCBs (mean $=5.6 \mathrm{ppb} ; p=0.0002$ ) as compared to women from other parts of the country (mean DDE $=6.3$; mean $\mathrm{PCBs}=4.5 \mathrm{ppb}$ ). Levels of DDE could not be predicted from consumption of meat, fish, poultry, dairy products, vegetables, fruits, and grains. There was a positive association between fish consumption and PCB concentrations among women in the Northeast and Midwest. Using data from the cases in the nested case-control study to assess the predictive ability of the models, we confirmed that the most reliable predictors of DDE were age and serum cholesterol, and the most important predictors of PCBs were age, serum cholesterol, and residence in the Midwest or Northeast. The null results for the majority of the food variables suggest that specific dietary factors, other than fish, are not currently a substantial contributor to human exposure to DDE and PCBs. Key words: DDE, DDT, PCBs, plasma, polychlorinated biphenyls. Environ Health Perspect 107:75-81 (1999). [Online 14 December 1998]

http://ehpnet1.niehs.nih.gov/docs/1999/107p75-81laden/abstract.html
\end{abstract}

Concern about possible adverse health effects, including a possible role in the etiology of hormonal disease such as breast cancer, associated with exposure to dichlorodiphenyltrichloroethane (DDT), dichlorodiphenyldichloroethylene (DDE), and polychlorinated biphenyls (PCBs) has prompted research into the determinants of blood levels of these chemicals in the general population. DDT, an insecticide, was used for agricultural purposes, as well as in public health programs to eradicate malaria (1). DDE is an environmental degradation product and the main metabolite of DDT. DDT was manufactured and used in the United States from 1945 until it was banned in 1972 (2) due to its adverse affects on wildlife (3). Mixtures of PCB congeners were used for many industrial purposes such as coolants and lubricants in transformers and capacitors; as plasticizers, surface coatings, adhesives, and inks; as immersion oils for microscopes; and for microencapsulation of dyes in carbonless duplicating paper (2). PCBs were produced in the United States from 1929 until 1977.

Since the 1940 s, the entire U.S. population has been exposed to at least low levels of DDT, its related compounds, and PCBs $(2,4)$. These compounds are stored in adipose tissue, the lipid components of blood, and breast milk. They are resistant to metabolism and have long half-lives; therefore, measurements in humans potentially represent cumulative exposures over many years $(5,6)$. Although adipose levels in the general population have decreased $(2,7)$, residues of these organochlorines are still detected in the majority of persons living in the United States (3).

DDT, DDE, and PCBs are persistent lipophilic compounds and highly resistant to biodegradation in the environment. Even today, many years after manufacture in the United States ceased, they are ubiquitous in air, soil, water, and sediments, albeit at levels much lower than observed in earlier decades $(5,6,8)$. Continuing introduction of DDT and PCBs into the environment occurs in the United States through industrial accidents, improper disposal of old industrial products, and the import of foodstuffs from developing countries where DDT is still used. The primary source of exposure to the general population is through the food chain; these compounds are stored in the fat of fish and dairy and meat products $(1,5,6,8,9)$. Fish obtain organochlorines from the sediments of fresh water bodies; for example, high levels of DDT and PCBs have been repeatedly measured in fish caught in the Great Lakes $(10,11)$. Dairy and beef cattle and poultry and eggs have been exposed to PCBs from animal feed stored in contaminated silos $(12,13)$, as well as from DDT and PCBs in the general environment. Residues of these organochlorines have also been measured in fruits, vegetables, and grains (14).

In this study we evaluated the predictors of plasma concentrations of DDE and PCBs in a group of U.S. women. We considered personal attributes such as age, dietary cholesterol, place of residence, body mass index, and lactation history, as well as extensive dietary intake information collected prior to blood sampling. We chose to evaluate levels of DDE as opposed to DDT because it is found in higher concentrations in blood (15) and is a better reflection of long-term exposure (16).

\section{Methods}

\section{Study Population}

We studied 480 women who were included in a case-control study of organochlorines and risk of breast cancer, nested in the Nurses' Health Study cohort (17). The Nurses' Health Study is an ongoing prospective cohort study established in 1976 when 121,700 registered nurses completed a mailed questionnaire that included items about known or suspected risk factors for breast cancer and other diseases. At enrollment, the participants were between the ages of 30 and 55 years of age and resided in 11 large states in the four regions of the continental United States (Northeast: Connecticut, Massachusetts, New Jersey, New York, Pennsylvania;

Address correspondence to F. Laden, Channing Laboratory, 181 Longwood Avenue, Boston, MA 02115 USA.

We thank the registered nurses who participated in this study, Rachel Meyer, Michelle LaChance, Kathryn Starzyk, Nancy Niguidula, Dorota Gertig, Sherry Yuan, and Sidney Atwood.

Supported by grants U01 CA/ES62984, CA40356, and CA49449 from the National Institutes of Health, by an Institutional National Service Award (5 T32 CA09001-19 to F.L.), and by an American Cancer Society Faculty Research Award (FRA-455 to D.J.H.). Received 22 June 1998; accepted 4 September 1998. 
Midwest: Michigan, Ohio; South: Florida, Maryland, Texas; West: California). In 1989-1990, 32,826 women sent us one blood sample each, using methods previously described (18). Cases eligible for the nested case-control study were women who did not have a diagnosis of cancer (other than nonmelanoma skin cancer) at the time of blood draw and who were subsequently diagnosed with breast cancer prior to 1 June 1992; there were 240 eligible cases. For each case we matched a control on year of birth, menopausal status, month and time of day of blood collection, fasting status at blood draw, and postmenopausal hormone use. To avoid the possibility of any influence of disease on the status of the potential predictors and their relationship to metabolism or storage of DDE and PCBs and to maximize the generalizability of our results, the primary analyses were conducted with data from the 240 control subjects only. Because we did not observe a significant difference in measured levels of PCBs and DDE between cases and controls (17), we used the data from the 240 cases as a validation data set to assess whether associations observed among the controls were reproducible.

\section{Exposure Information}

Participants in the Nurses' Health Study have completed biennial questionnaires updating information on demographic, lifestyle, and medical characteristics since 1976. Each participant in the blood cohort also completed a questionnaire at the time of blood draw. We derived information on possible predictors of $\mathrm{PCBs}$ and DDE from either this supplemental questionnaire or the main Nurses' Health Study questionnaire administered in 1986. We considered region of residence in 1986; $8 \%$ of the nurses had moved from their 1976 region of residence. The states represented in the study included the original 11 and New Hampshire in the Northeast; Georgia, Louisiana, North Carolina, and Virginia in the South; and New Mexico, Oregon, and Washington in the West.

We obtained dietary information in 1986 with a semiquantitative food frequency questionnaire. We asked subjects to indicate how often, on the average, they consumed specified amounts of 136 food items. There were nine possible responses for each food item, ranging from never to six or more times per day. We also obtained frequency information on intake of 61 foods in 1980 , and used these data to assess associations with diet further in the past, closer to the time when DDT and PCBs were still in use. Details of the results of validation studies of the food frequency questionnaire have been described elsewhere (19).

\section{Laboratory Analyses}

The laboratory methods have been previously described in detail $(20,21)$. Briefly, a polar extract of plasma lipids was further treated with a column chromatographic clean-up and enrichment step and then analyzed by gas chromatography with electron capture detection. All steps were scaled appropriately for $0.50-\mathrm{ml}$ aliquot volumes. We previously demonstrated, using Nurses' Health Study specimens, that the precision with the use of this volume and an optimized analytic procedure is similar to that with previous procedures using 1-ml and 2-ml aliquots (22). The amount of methanol was optimized $(0.3 \mathrm{ml})$ to create a good interface between the aqueous layer and the ether-hexane extractant $(1.25 \mathrm{ml})$. Results are reported in parts per billion (ppb), i.e., nanograms per milliliter. PCBs are the sum of 16 higher PCB congeners, those with retention times longer than that of DDE (penta-, hexa-, and heptachlorobiphenyls). On average, four individual congeners [International Union of Pure and Applied Chemistry (IUPAC) $118,180,138$, and 153 ] constituted $73 \%$ of the total PCBs. The detection limits were less than $1 \mathrm{ppb}$ for both DDE and PCBs, based on $3 \times$ the standard deviation (23) of 24 determinants of a quality control plasma pool having approximately $1 \mathrm{ppb} D D E$ and PCBs. Total plasma cholesterol was determined using a procedure described by Allain et al. (24).

Randomly ordered case-control pairs were sent to the laboratory in batches of 12 pairs; each batch included two blinded split samples from a pool of premenopausal or postmenopausal plasma. For each batch we calculated the coefficient of variation percentage (CV\%); the median $\mathrm{CV} \%$ for DDE was $4.3 \%$ and for PCBs, the median CV\% was $13.2 \%$. Values were missing for DDE (two cases and two controls) and PCBs (an additional two controls and four cases) due to lost samples or evidence of contamination.

\section{Statistical Analyses}

Nondietary predictors. The primary analyses used data from the controls. Spearman correlation coefficients were calculated to assess the association of age and total serum cholesterol with plasma levels of DDE and PCBs. The association of age- and cholesterol-adjusted levels of DDE and PCBs with each category of the potential nondietary predictors was obtained with analysis of variance (ANOVA) and tests for trend. Separate multivariate linear regression models were then performed using DDE and PCBs as the dependent variables and the nondietary variables as the explanatory variables. The contribution of each variable was evaluated with the partial $\mathrm{F}$ test and examination of the change in the model $R^{2}$ (25). The values of DDE and PCBs were log-normally distributed. Therefore, to account for the heteroskedasticity and nonnormality of the regression residuals, the asymptotic covariance matrix was used to calculate the robust variance (26).

The reproducibility of the associations observed in the controls was tested in the cases ("validation" data set). The regression equations estimated from the control data set were used to predict the levels of the organochlorines for each individual in the validation data set, and these were compared to the observed values. The equations for DDE and PCBs that yielded the highest Spearman correlation coefficient between the predicted and observed levels were considered the best prediction equation for DDE and PCBs, respectively.

Five DDE observations and two PCB observations were identified as potential outliers among the controls because their values were more than three interquartile ranges above the 75 th percentile (27). All analyses were repeated with these observations excluded.

Dietary predictors. Subjects who did not answer the food frequency questionnaire or who were missing information on 30 or more of the 136 food items were excluded from the analysis. Twenty-five people met this criteria, 23 of whom had not answered the dietary questionnaire. For the remaining subjects, blank responses for individual foods were assumed to indicate zero intake of that food. We scaled the responses to times per day and modeled each food as a continuous variable. To decrease the potential spurious influence of extreme values of food frequencies, the upper categories of intake were collapsed until there were at least five observations in the category representing most frequent consumption.

Based on prior publications on the foods that contribute most to organochlorine intake, we focused our primary diet analysis on the 94 food items included in the following food groups: meat, chicken, fish, eggs, dairy, vegetables, fruit, and grains. To determine if any single food item was a significant predictor of organo-chlorine levels, DDE and PCB levels were regressed independently on each food, one at a time. Each food was evaluated in univariate models as well as in models with age, total cholesterol, and region included. The contribution of each group of foods was evaluated by fitting multiple regression models with parameters for age, total cholesterol, region, and for all foods in the group and calculating the loglikelihood ratio test statistic for the group of food parameters. 
To develop a prediction equation using all available food item information, the "max-

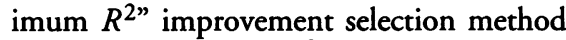
was employed. The $R^{2}$ (the square of the Pearson correlation coefficient) provides an estimate of the percentage of variation explained by the regression equation. Thus, for each number of parameters, this technique finds the model that explains the most variation. All 136 food items were given the same opportunity to enter into the model after age, cholesterol, and region were forced in. Models with up to 50 dietary variables included were estimated, and the reproducibility of each model was assessed using the validation data set. All analyses were performed with and without the identified potential outliers included and using the original diet values as well as the collapsed values.

The Spearman correlation coefficient between the measured levels of DDE and DDE exposure scores derived from the U.S. Food and Drug Administration (FDA) Total Diet Study 1986-1991 (28) was also used to test the association of reported diet with DDE in blood plasma. An individual's average daily dietary exposure to $\mathrm{DDE}$ was estimated by combining contaminant residue data in table-ready foods with data on their annual diet in 1990, as measured by the food frequency questionnaire (29). Comparable information on PCBs was not available due to the preponderance of nondetects for PCB residues in the Total Diet Study database (28).

\section{Results}

Plasma concentrations of DDE ranged from 0.14 to $39.44 \mathrm{ppb}$, with a mean \pm standard deviation (SD) of $7.09 \pm 6.06$ in the control series (range 0.19-24.66 ppb) and with a mean $\pm S D$ of $6.12 \pm 4.58$ in the case series. Total plasma PCBs ranged from 1.61 to $16.62 \mathrm{ppb}$ (mean $\pm S D=$ $5.22 \pm 2.35$ ), and from 1.55 to $17.44 \mathrm{ppb}$ (mean $\pm \mathrm{SD}=5.15 \pm 2.77$ ) in the control and case series, respectively. Comparisons of the distribution of breast cancer risk factors for the controls and cases have been published elsewhere (17).

\section{Nondietary Predictors}

Age and serum cholesterol were positively correlated with both DDE and PCBs. Age at blood draw ranged from 43 to 69 years old (mean $\pm \mathrm{SD}=57.7 \pm 7.4$ ); the Spearman correlation coefficients between age and DDE and PCBs were $r=0.37$ and $r=0.26$, respectively ( $p=0.0001$ for each). Total serum cholesterol levels ranged from 131 to 414.6 $\mathrm{mg} / \mathrm{dl}($ mean $\pm \mathrm{SD}=226.1 \pm 38.7)$. The Spearman correlation coefficient for cholesterol with DDE was $r=0.15(p=0.02)$ and with PCBs was $r=0.23(p=0.0003)$.
The age- and cholesterol-adjusted means of DDE and PCBs for categories of region in 1986, parity, age at first birth, lactation, body mass index, and waist-to-hip ratio are presented in Table 1. DDE levels of residents in the western states were significantly higher than those of other women (West: mean $=11.0$; elsewhere: mean $=6.3 ; p=$ 0.003). Parity was unrelated to DDE, but the 17 women with late age at first birth (over age 30) had significantly higher levels of DDE, even after adjustment for parity and history of lactation. There was some indication that DDE levels decreased with duration of past lactation, but this trend was not significant. Also, among the 56 women who lactated for 6 months or more, there was no evidence of an inverse linear relationship; the 10 women who lactated more than 24 months had a mean concentration of $7.46 \mathrm{ppb}$, while the mean for the remaining 46 women was $6.11 \mathrm{ppb}(p=0.50)$. Mean DDE levels increased slightly with increasing quartiles of body mass index, but the test for trend was not statistically significant. In the multiple regression model controlling for age, cholesterol, residence in the West, body mass index, parity, and lactation, we found that age, cholesterol, and region remained statistically significant predictors for DDE (Table 2). Lactation greater than 6 months was of borderline statistical significance. Validation of the various models showed that age and cholesterol were the most important predictors of DDE (Table 3). The addition of other variables, including region, did not improve the predictive ability of the model.

The five women with the highest concentrations of DDE (identified as potential outliers) lived in California, and four out of the five had never breast-fed their infants. Removal of these observations did not materially alter the results from those presented above, although the estimates for region and lactation were attenuated.

PCB concentrations were statistically significantly associated only with region of residence and parity (Table 1 ). Women residing in the Northeast and Midwest had higher concentrations of PCBs than women residing in the West and South (the mean for Northeast and Midwest was 5.6; the mean for other regions was $4.5 \mathrm{ppb} ; p=0.0002$ ). PCBs were also elevated in parous women,

Table 1. Age- and cholesterol-adjusted mean DDE and PCB levels for potential predictors

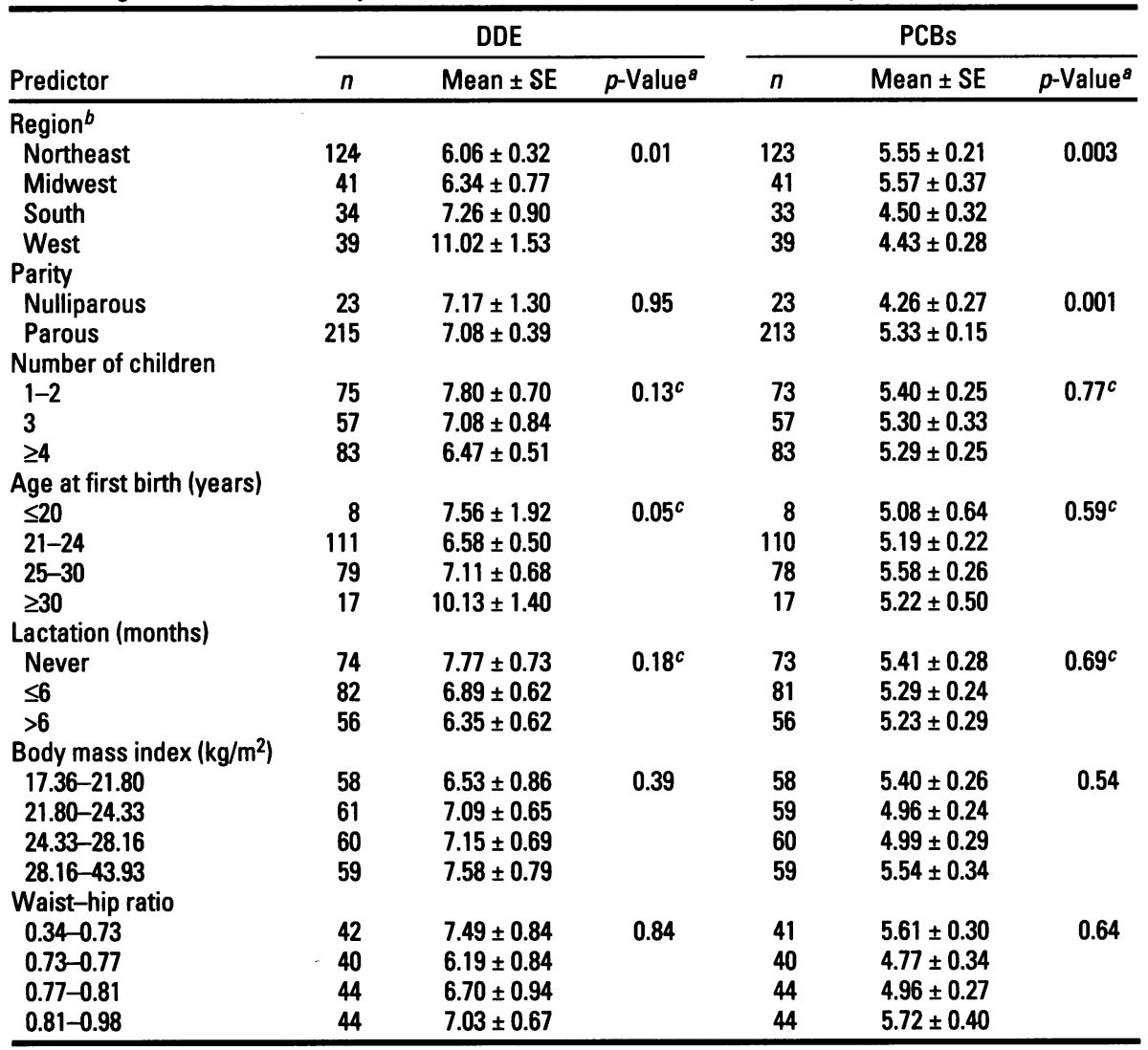

SE, standard error.

aHypothesis tests: analysis of variance (ANOVA) for region and parity; test for trend otherwise.

bRegions: Northeast: Connecticut $(n=11)$, Massachusetts $(n=21)$, New Hampshire $(n=1)$, New Jersey $(n=16)$, New York $(n=44)$, Pennsylvania $(n=33)$; Midwest: Michigan $(n=19)$, Ohio $(n=22)$; South: Florida $(n=14)$, Georgia $(n=1)$, Louisiana $(n=1)$, Maryland $(n=9)$, North Carolina $(n=2)$, Virginia $(n=1)$; West: California $(n=36)$, New Mexico $(n=1)$, Oregon $(n=1)$, Washington $(n=1)$.

cAmong parous women only. 
regardless of the number of children and age at first birth, compared to nulliparous women $(p=0.001)$. There was no relationship of PCBs with lactation, body mass index, or waist-hip ratio. Adjusting for all variables in a multivariate model confirmed these observations (Table 2). Age, cholesterol, and region were the only important predictors in the validation analysis (Table 3). As with DDE, the two women identified as potential outliers for PCB levels resided in the high risk region, in this case the Northeast. Again, omission of these observations did not materially change the results. Analyses of the four major congeners also showed significant associations with age, cholesterol, and region, with the exception of IUPAC 180; this congener was not associated with region.

\section{Dietary Predictors}

There were no meaningful associations between DDE and the dietary variables.
Table 2. Multivariate models for DDE and PCBs regressed on nondietary variables

\begin{tabular}{|c|c|c|c|c|}
\hline \multirow[b]{2}{*}{ Variables } & \multicolumn{2}{|c|}{ DDE } & \multicolumn{2}{|c|}{ PCBs } \\
\hline & Change (in ppb) & $p$-Value & Change (in ppb) & $p$-Value \\
\hline $\begin{array}{l}\text { Age (years) } \\
\text { Cholesterol (10 mg/dl) } \\
\text { Region }{ }^{a} \\
\text { Body mass index }{ }^{b} \\
\text { Parityc } \\
\text { Lactation } \leq 6 \text { months } \\
\text { Lactation }>6 \text { months }\end{array}$ & $\begin{array}{r}0.17 \\
0.20 \\
5.01 \\
0.16 \\
0.93 \\
-1.20 \\
-1.69\end{array}$ & $\begin{array}{l}0.0003 \\
0.02 \\
0.001 \\
0.13 \\
0.49 \\
0.18 \\
0.06\end{array}$ & $\begin{array}{r}0.08 \\
0.13 \\
1.09 \\
-0.01 \\
1.04 \\
0.00 \\
-0.16\end{array}$ & $\begin{array}{l}0.0001 \\
0.001 \\
0.0002 \\
0.87 \\
0.004 \\
0.99 \\
0.69\end{array}$ \\
\hline
\end{tabular}

$R^{2}$ is 0.21 for DDE and 0.17 for PCBs.

aRegion = West for DDE and Northeast and Midwest for PCBs.

bQuartiles of body mass index $\left(\mathrm{kg} / \mathrm{m}^{2}\right)$, categorical variable.

cParity = parous versus nulliparous.

Table 3. Validation of models estimated in the control data set for DDE and PCBs: correlation coefficients between observed and predicted values in the validation data set

\begin{tabular}{llc}
\hline & \multicolumn{2}{c}{ Spearman correlation coefficients } \\
\cline { 2 - 3 } Model & DDE & PCBs \\
\hline Age & 0.30 & 0.28 \\
Cholesterol & 0.27 & 0.31 \\
Region & 0.18 & 0.19 \\
Age + cholesterol & 0.38 & 0.40 \\
Age + cholesterol + region & 0.38 & 0.47 \\
Age + cholesterol + region + BMI & 0.36 & 0.47 \\
Age + cholesterol + region + parity & 0.38 & 0.46 \\
Age + cholesterol + region + lactation variables & 0.38 & 0.46 \\
Age + cholesterol + region + BMI + parity + lactation variables & 0.35 & 0.46 \\
\hline
\end{tabular}

BMI, body mass index.

${ }^{a}$ All correlation coefficients are statistically significant at $p \leq 0.01$.

Table 4. Contribution of food groups to the prediction equation with age, cholesterol, and region ${ }^{a}$

\begin{tabular}{|c|c|c|c|c|c|}
\hline \multirow[b]{2}{*}{ Food group $b$} & \multirow{2}{*}{$\begin{array}{l}\text { Variables } \\
\text { in group }(n)\end{array}$} & \multicolumn{2}{|c|}{ DDE } & \multicolumn{2}{|c|}{ PCBs } \\
\hline & & $R^{2}$ & $p$-Value ${ }^{c}$ & $R^{2}$ & $p$-Value ${ }^{c}$ \\
\hline None & & 0.15 & - & 0.14 & - \\
\hline Meat & 8 & 0.19 & 0.28 & 0.16 & 0.84 \\
\hline Chicken & 2 & 0.17 & 0.16 & 0.15 & 0.33 \\
\hline Fish (all) & 4 & 0.16 & 0.72 & 0.19 & 0.01 \\
\hline Dark and other fish & 2 & 0.16 & 0.76 & 0.16 & 0.07 \\
\hline Egg & 1 & 0.16 & 0.64 & 0.17 & 0.005 \\
\hline Dairy & 10 & 0.21 & 0.21 & 0.18 & 0.46 \\
\hline Vegetables & 34 & 0.28 & 0.52 & 0.29 & 0.17 \\
\hline Fruit & 22 & 0.21 & 0.85 & 0.24 & 0.29 \\
\hline Grain & 12 & 0.20 & 0.55 & 0.17 & 0.82 \\
\hline
\end{tabular}

aRegion is West in analyses of DDE and Northeast and Midwest in analyses of PCBs.

bServings per day. Meat includes processed meats; hamburger; beef, pork, or lamb as a main course; beef, pork, or lamb in a mixed course; hot dogs; beef liver; chicken liver; and bacon. Chicken includes chicken or turkey with skin and chicken or turkey without skin. Fish includes dark-meat fish, canned tuna, other fish, shrimp, and other shellfish. Dairy includes skim milk, whole milk, cream cheese, sour cream, ice cream, cottage cheese, other cheese, butter, and yogurt. Vegetables includes string beans, broccoli, sauerkraut, coleslaw, cooked cabbage, cauliflower, brussels sprouts, raw carrots, cooked carrots, corn, peas, mixed vegetables, beans, alfalfa sprouts, celery, mushrooms, yellow squash, eggplant, yams, cooked spinach, raw spinach, kale, iceberg lettuce, romaine lettuce, green peppers, cucumbers, tomatoes, tomato juice, tomato sauce, chili sauce, tofu, fried potatoes, potatoes, and potato chips. Fruit includes raisins, avocados, bananas, cantaloupes, watermelons, apples, apple sauce, apple juice, pears, canned pears, peaches, canned peaches, fruit cocktail, strawberries, blueberries prunes, oranges, orange juice, grapefruits, grapefruit juice, other juice, and jam. Grain includes cereal, oatmeal, cooked cereal, white bread, dark bread, English muffin, muffin, brown rice, white rice, pasta, pancakes, and other grains.

${ }_{c p}$-Value from log likelihood ratio test for the group of variables, given that age, cholesterol, and region are in the model.
Ninety-four food items classified as either meat, chicken, fish, eggs, dairy, vegetables, fruits, or grain were included on the 1986 food frequency questionnaire. None of these food groups contributed significantly to the model controlling for age, cholesterol, and residence in the West (Table 4).

We estimated prediction equations for DDE using the full set of dietary variables and assessed the contribution of the dietary variables to the predictive ability of the models in the validation data set. The models with age, cholesterol, region, and one additional variable, two additional variables, three additional variables, and up to 10 additional variables are presented in Table 5. Slightly different sets of variables were selected, depending on whether we used the original values or the collapsed values for each diet item or if we omitted the observations in the extreme categories. In any case, the dietary variables that entered the DDE model based on their contribution to the model fit were either not foods identified in the previous literature as sources of DDE exposure or they had negative coefficients. We chose to present in Table 5 (as well as in Tables 4 and 6) the models obtained with the collapsed values because they used all of the available data and were less dependent on extreme points that might be inconsistent with the majority of the data. Although the fit of the model improved with additional parameters and the coefficients for all individual food parameters were significant at $p<0.05$, the predictive ability of the model, as measured by the validation data set, actually decreased with the inclusion of the food variables.

As a further test of the relationship between the diet information collected by the food frequency questionnaire and the levels of DDE measured in the plasma samples, we calculated the Spearman correlation coefficient comparing the measured levels, adjusted for age and cholesterol, with the average daily dietary exposure to DDE estimated from the FDA Total Diet Study 1986-1991 and the 1990 food frequency questionnaire. These two values were not correlated $(r=0.03, p=0.66)$.

Eggs and fish were statistically significant predictors for PCB levels, controlling for age, cholesterol, and residence in the Northeast or Midwest (Table 4). The fish group included variables for dark-meat fish (e.g., mackerel, salmon, sardines, bluefish, and swordfish), other fish, canned tuna, and shellfish. The coefficient for dark-meat fish was 8.6 ( $p=$ 0.003 ) and the coefficient for shellfish was $-8.4(p=0.01)$; the coefficients for other fish and canned tuna were not statistically significant. The log-likelihood ratio test for the four variables of the fish group incorporated the 
Table 5. Validation of models including dietary variable as indicated by $R^{2}$ from the best model, with age, cholesterol, region, and up to 10 additional variables estimated in the control data set, and Spearman correlation coefficients between observed and predicted values of DDE and PCBs

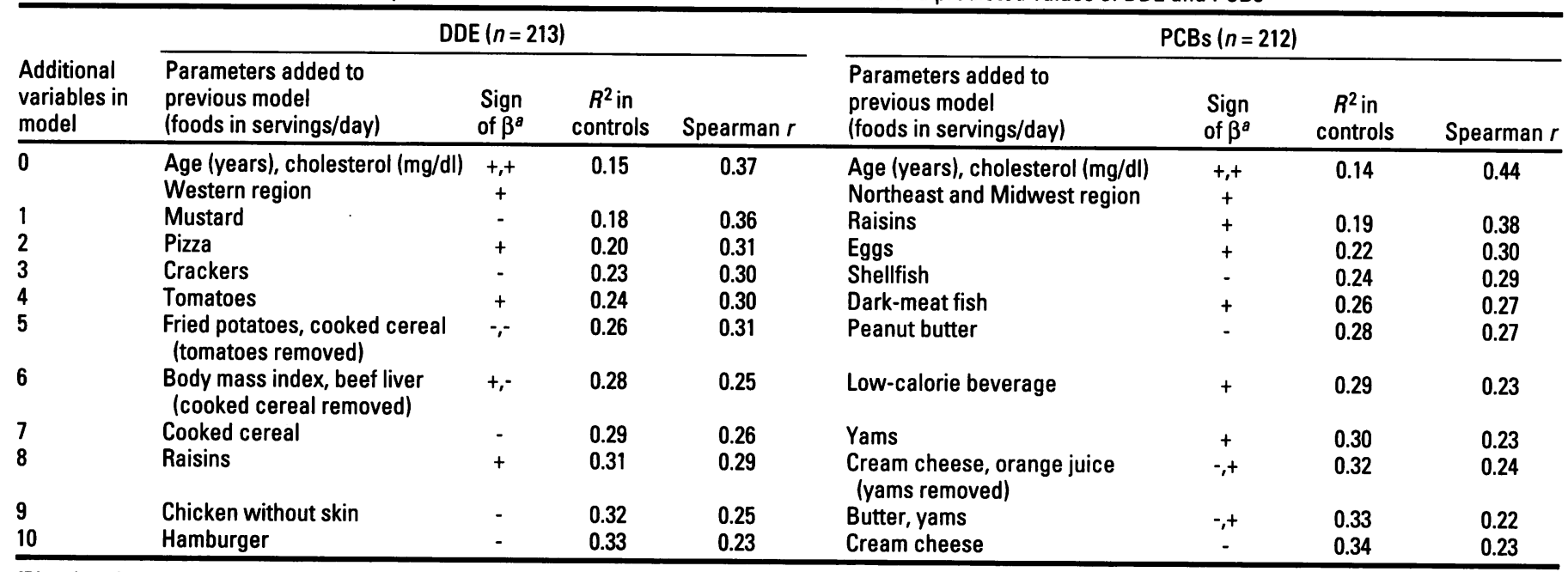

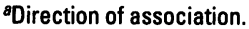

positive coefficient for dark-meat fish as well as the negative coefficient for shellfish.

Because the PCB concentration in locally caught fish and locally grown eggs could vary by region, we explored fish and egg intake in regression analyses stratified by region. Eggs and fish (defined either as darkmeat fish only, other fish, or a combined score of both types) were positive predictors of PCB levels for residents of the Northeast and Midwest (Table 6) but not for residents of the West and South. In congener-specific analyses, all four main congeners were positively associated with the summary variable for fish consumption. The regression coefficient was statistically significant for congeners $118(p=0.02), 138(p=0.02)$, and $153(p=0.01)$, but not for $180(p=0.18)$.

As with DDE, the addition of food parameters to the model did not improve its predictive ability in the validation data set (Table 5).

Removing the potential outliers of DDE and PCBs did not substantially alter the above results. We also repeated these analyses using the diet information collected in 1980, and we did not observe the positive relationships with foods expected to contain higher levels of organochlorines.

\section{Discussion}

The objective of this study was to identify the predictors of plasma levels of DDE and PCBs in a group of U.S. women. We found that levels of DDE and PCBs were positively associated with age and serum cholesterol. Compared to other women, women who resided in the western region of the United States (represented predominantly by California) had higher levels of DDE, and women living in the Northeast and Midwest had elevated levels of PCBs. Dietary information obtained from a food frequency questionnaire 2-3 years before blood draw did not predict concentrations of DDE. There was some evidence of a positive association between fish and egg consumption and PCB concentrations, specifically in women residing in the Northeast and Midwest. Using a group of women with breast cancer as a validation data set, we determined that the most important predictors of DDE and PCBs were age and cholesterol; addition of other variables to the model did not improve its predictive ability.

Previous studies have consistently observed a positive correlation between age and blood levels of DDE and PCBs $(2,15,30,31)$. This phenomenon is probably a function both of age itself and of a birth cohort effect. Older women had a greater opportunity for high level exposures to these compounds because they were alive longer during the period when DDT and PCBs were manufactured and used in the United States. In addition, they have had a longer time to accumulate the metabolites of these compounds in their body. It has also been suggested that metabolism of these compounds might slow down with age (9).

$\mathrm{DDE}$ and $\mathrm{PCB}$ are stored in adipose tissue and in the lipid component of blood plasma. It is common practice in the published literature to adjust the plasma concentration of DDE and PCBs by total cholesterol and triglycerides and present the information as a component of lipid $(32,33)$. Because total blood lipids were not available to us, we adjusted for total cholesterol in the regression equations. As expected, total cholesterol levels were positively associated with levels of DDE and PCBs (31).
Table 6. Regression coefficients for eggs and fish among residents of the Northeast and Midwest, controlling for age and plasma cholesterol $(n=$ 152)

\begin{tabular}{lcc}
\hline $\begin{array}{l}\text { Food } \\
\text { (servings/day) }\end{array}$ & $\begin{array}{c}\text { Change in } \\
\text { PCBs (ppb) }\end{array}$ & $p$-Value \\
\hline Dark-meat fish & 10.38 & 0.002 \\
Other fish & 3.28 & 0.10 \\
Dark-meat fish + other fish & 4.19 & 0.01 \\
Eggs & 2.04 & 0.14 \\
Shellfish & -7.33 & 0.05 \\
\hline
\end{tabular}

Despite the fact that in each region only a subset of states are represented by the Nurses' Health Study, the regional variation in DDE (highest in the West) and PCB levels (highest in the Northeast and Midwest) reflects the history of the geographic manufacture and use of these chemicals. Data from the Second National Health and Nutrition Examination Survey (NHANES II) showed that populations living in the South and West had higher levels of pesticides in their blood as compared to the rest of the U.S. population (15). Higher concentrations of PCBs in human tissues have consistently been measured in the Northeast and Midwest than in the rest of the United States. From 1972 to 1983 , the EPA found that greater percentages of individuals residing in the Northeast were in the highest adipose tissue level category (2). In conjunction with these observations, the U.S. Fish and Wildlife Service survey of concentrations of organochlorine compounds in freshwater bodies in 1981 and 1984 recorded the highest concentrations of PCBs in sites located in the industrial regions of the Northeast, the Great Lakes, and in the upper Mississippi River (34).

Because organochlorines and their metabolites are stored in adipose tissue, we expected to see an association between 
body mass index, a measure of adiposity, and plasma levels of these compounds. In a study of fish eaters from the Great Lakes region, body mass index was a positive predictor of serum DDT in multivariate analyses, but not of PCBs (35). A recent multicenter study in Europe observed similar results for concentrations of DDE in adipose tissue (36), and a study in Long Island, New York, found a correlation of body mass index with DDE in both media (30). We did not observe any statistically significant associations with our plasma specimens and body mass index; however, there was a suggestion of a positive association with DDE.

Lactation is the primary means of excretion of DDE and PCBs. In a study of concentrations of these compounds in breast milk, levels were highest in the first lactation period and declined both with time spent breast-feeding and with number of children nursed (37). In our study, we did not observe a significant association of DDE and PCBs with duration of lactation although there was a suggestion of an inverse relation with DDE. Parous women had statistically significant elevated levels of PCBs as compared to nulliparous women. In this study population, only 10 women lactated for a total of over 24 months, and most of the women would have lactated at least 10 years prior to blood draw. It is possible that we did not detect decreases in DDE or PCBs due to either the short durations of lactation or because these women lactated too far in the past; organochlorine exposure subsequent to lactation may have reduced the influence of lactation on plasma organochlorine levels in this age group.

The general population of the United States and other developed countries was thought to be exposed to both DDE and PCBs predominantly through residues in foods. Dairy products, meat, fish, poultry, and eggs have been hypothesized to represent the primary contribution of DDT and DDE to the U.S. diet. These residues have also been measured at much lower levels in vegetables, grains, and cereals $(14,38)$.

A recent study in a German population of men and women 65-74 years of age measured plasma organochlorine levels and consumption of 32 food groups using a 7day diet questionnaire administered concurrent to blood draw. They observed only modest, although statistically significant, positive correlations between consumption of beef and lamb and DDT $(r=0.18)$ and PCBs $(r=0.13)$ and between saltwater fish and PCBs $(r=0.12)(39)$.

We did not observe associations between levels of DDE and intake of meat, dairy, poultry, and fish in the expected direction. Fruits and vegetables as a group also did not predict DDE. In addition, there was no relationship between the observed plasma DDE concentrations and the average daily dietary exposure to DDE estimated from levels measured in different foods as part of a market-basket survey.

The highest concentrations of PCBs have been measured in fish $(31,40)$, particularly bottom- dwelling fish, from PCBcontaminated waters such as the Great Lakes. In general, PCB- and DDT-contaminated fish are caught by local sport fishing and are not those fish obtained in the market $(5,6,35)$. PCBs have also been measured in meat, poultry, dairy products, and eggs (G). In this study, consumption of darkmeat fish and eggs were positive predictors of PCBs among participants residing in the Northeast and Midwest. These observations suggest that fish and eggs obtained regionally may be an ongoing source of exposure to PCBs in this population. As with DDE, meat, dairy, and poultry did not predict plasma PCB concentrations.

There are a number of possible explanations why we did not observe associations between diet and levels of DDE, and diet other than fish and eggs and PCBs. Levels of DDT, DDE, and PCBs in the food supply have been decreasing substantially over time (9). For example, the estimated dietary intake of DDT and metabolites in the United States was 240 $\mu \mathrm{g} / \mathrm{man} /$ day in 1970 and $8 \mu \mathrm{g} / \mathrm{man} /$ day in 1974 (41). For the period 1984-1986, women of the age range covered in this study consumed approximately $0.7 \mu \mathrm{g} /$ day of total DDT and $0.1 \mu \mathrm{g} /$ day of PCBs, on average (42). Also, concentrations in Great Lakes fish have been decreasing. Hovinga et al. (35) found that in 1982 current fish consumption was an important risk factor for serum DDT and PCB levels; however, in 1989 fish consumption in the past was the more relevant exposure. Thus, foods consumed in 1986 might not have had significant levels of these contaminants.

In addition, because of the long halflives of DDE and PCBs and their history of use, changes in diet during the years before exposure assessment might have masked our ability to observe an association with diet. In an attempt to address this limitation, we repeated our analyses with diet information from a reduced food frequency questionnaire administered in 1980. No significant associations with diet from this time period and either chemical were observed.

Levels of organochlorines in food may vary substantially depending on the source of the food. Home-grown produce from residences with high soil contents of DDT and PCBs could have higher levels of these compounds than store-bought fruits and vegetables; Cullen et al. (43) found that tomatoes grown in a PCB-contaminated area had elevated levels of PCBs. Our inability to discriminate between foods that had the opportunity to be contaminated and those that did not may have diluted the predictive value of the contaminated foods.

It is also possible that the food frequency questionnaire in general was not a sufficient instrument for predicting plasma levels of contaminants. However, previous studies using this instrument have been able to show expected relationships between reported food consumption and levels of nutrients and contaminants measured in biological specimens. For example, fish consumption predicted mercury levels in toenails (44), and the food frequency questionnaire predicted levels of $\beta$-carotene and $\alpha$-tocopherol in plasma (45) and relative levels of polyunsaturated and trans fatty acids in adipose tissue (46). There are few published studies comparing food intake directly with plasma levels of DDE and PCBs, with the exception of the evaluation of contaminated fish intake. The actual levels and/or the bioavailability of DDE and PCBs in other foods might be too low to be directly detected in plasma.

An additional limitation of this study is the relatively small sample size. We only had DDE and PCB measurements available for 238 and 236 women, respectively, and the sample size available for the diet analysis was even smaller (213 for DDE, 212 for PCBs). Therefore, we may not have had the power to detect weak nondietary and dietary associations.

Errors in the measurements of DDE and PCBs may have prevented us from detecting any hypothesized associations. Measurement error in the outcome variable will not lead to bias in the regression coefficients; however, it will increase the variance. There was considerable batch-to-batch variability of PCB measurements, but not DDE measurements, but the coefficient of variation obtained from the analysis of blinded specimens was relatively low. The fact that we saw the expected statistically significant associations between age, serum cholesterol, and region is reassuring. We did not distinguish between PCB congeners. Different congeners have been detected in specific foods $(47,48)$; as analytic methods that permit accurate assessment of specific congeners become available, examination of specific PCBs may refine associations with diet and other predictors.

In conclusion, age, serum cholesterol, and region of residence are strong predictors of plasma concentrations of DDE and 
PCBs. Consumption of meat, poultry, dairy, vegetables, and fruits were not predictors of higher levels of these compounds. However, there was some evidence that fish consumption specifically among the population residing in the Northeast and the Midwest, where contamination of sport fish has been documented, was associated with levels of PCBs. These results suggest that specific dietary factors other than fish are not currently a substantial determinant of recent human exposure to DDT and PCBs in the United States.

\section{References and Notes}

1. López-Carrillo L, Torres-Arreola L, Torres-Sánchez L, Espinosa-Torres F, Jiminéz C, Cebrian M, Waliszewski S, Saldate 0 . Is DDT use a public health problem in Mexico? Environ Health Perspect 104:584-588 (1996).

2. Kutz FW, Wood PH, Bottimore DP. Organochlorine pesticides and polychlorinated biphenyls in human adipose tissue. Rev Environ Contam Toxicol 120:1-82 (1991).

3. Wolff MS. Pesticides-how research has succeeded and failed in informing policy: DDT and the link with breast cancer. Environ Health Perspect 103/suppl 6):87-91 (1995).

4. Levine R. Recognized and possible effects of pesticides in humans. In: Handbook of Pesticide Toxicology, Vol 1 (Hayes WJ Jr, Laws ER Jr, eds). San Diego, CA:Academic Press, Inc., 1991;275-360.

5. ATSDR. Toxicological Profile for $4,4^{\prime}-D D T, 4,4^{\prime}-D D E$, 4,4'-DDD. Atlanta, GA:Agency for Toxic Substances and Disease Registry, 1992

6. ATSDR. Selected PCBs (Aroclor-1260, 1254,-1248, $-1242,-1232,-1221$, and -1016). Atlanta, GA:Agency for Toxic Substances and Disease Registry, 1993.

7. Robinson PE, Mack GA, Remmers J, Levy $R$, Mohadjers $L$. Trends of PCB, hexachlorobenzene, and beta-benzene hexachloride levels in the adipose tissue of the US population. Environ Res 53:175-192 (1990).

8. WHO. Polychlorinated Biphenyls and Terphenyls. Environmental Health Criteria 140. Geneva:World Health Organization, 1993.

9. Ahlborg UG, Lipworth L, Titus-Ernstoff L, Hsieh C-C, Hanberg A, Baron J, Trichopoulos D, Adami H-O. Organochlorine compounds in relation to breast cancer, endometrial cancer, and endometriosis: an assessment of the biological and epidemiological evidence. Crit Rev Toxicol 25:463-531 (1995).

10. Veith GD, Kuehl DW, Leonard EN, Welch K, Pratt G Polychlorinated biphenyls and other organic chemical residues in fish from major United States watersheds near the Great Lakes, 1978. Pestic Monit J 15:1-8 (1981).

11. Foran JA, Cox M, Croxton D. Sport fish consumption advisories and projected cancer risks in the Great Lakes basin. Am J Public Health 79:322-325 (1989).

12. Willett LB, Liu T-TY, Durst HI, Cardwell BD, Renkie ED. Quantification and distribution of polychlorinated biphenyls in farm silos. Bull Environ Contam Toxicol 35:51-60 (1985).

13. Schantz SL, Jacobson JL, Humphrey HEB, Jacobson SW, Welch R, Gasior D. Determinants of polychlorinated biphenyls (PCBs) in the sera of mothers and children from Michigan farms with PCB-contaminated silos. Arch Environ Health 49:452-458 (1994).

14. Spear R. Recognized and possible exposure to pesticides. In: Handbook of Pesticide Toxicology, Vol 1
(Hayes WJ Jr, Laws ER Jr, eds). San Diego, CA:Academic Press, Inc., 1991;245-274.

15. Stehr-Green PA. Demographic and seasonal influences on human serum pesticide residue levels. $J$ Toxicol Environ Health 27:405-421 (1989).

16. Smith AG. Chlorinated hydrocarbon insecticides. In Handbook of Pesticide Toxicology, Vol 2 (Hayes WJ Jr, Laws ER Jr, eds). San Diego, CA:Academic Press, Inc., 1991;731-950.

17. Hunter DJ, Hankinson SE, Laden F, Colditz GA Manson JE, Willett WC, Speizer FE, Wolff MS. Plasma organochlorine levels and the risk of breast cancer. N Engl J Med 337:1253-1258 (1997).

18. Hankinson SE, Willett WC, Manson JE, Hunter DJ, Coldtiz GA, Stampfer MJ, Longcope C, Speizer FE. Alcohol, height, and adiposity in relation to estrogen and prolactin levels in postmenopausal women. $J$ Natl Cancer Inst 87:1297-1302 (1995).

19. Willett WC, Sampson L, Stampfer MJ, Rosner B, Bain C, Witschi J, Hennekens $\mathrm{CH}$, Speizer $\mathrm{Ft}$. Reproducibility and validity of a semiquantitative food frequency questionnaire. Am J Epidemiol 122:51-65 (1985).

20. Wolff MS, Rivera M, Baker DB. Detection limits of organochlorine pesticides and related compounds in blood serum. Bull Environ Contam Toxicol 47:499-503 (1991).

21. Wolff MS, Toniolo PG, Lee EW, Rivera M, Dubin N. Blood levels of organochlorine residues and risk of breast cancer. J Natl Cancer Inst 85:648-652 (1993).

22. Laden F, Wolff MS, Niguidula NJ, Spiegelman D, Hankinson SE, Hunter DJ. Reduced aliquot size for a plasma organochlorine assay for use in epidemiological studies. Cancer Epidemiol Biomark Prev 6:333-338 (1997).

23. Long GL, Winefordner JD. Limit of detection: a closer look at the IUPAC definition. Anal Chem 55:712A-724A (1983).

24. Allain CC, Poon LS, Chan CS, Richmond W, Fu PC. Enzymatic determination of total serum cholesterol. Clin Chem 20:470-475 (1974)

25. Kleinbaum DG, Kupper LL, Muller KE. Applied Regression Analysis and Other Multivariablè Methods. Belmont, CA:Duxbury Press, 1988.

26. White $\mathrm{H}$. A heteroskedasticity-consistent covariance matrix estimator and a direct test for heteroskedasticity. Econometrica 48:817-838 (1980).

27. Tukey JW. Exploratory Data Analysis. Reading, MA:Addison-Wesley, 1977.

28. Tomerlin JR, Kidwell JL, Tucker KD, Chew S, Lee KH. Dietary Exposure Assessment Phase II Report, Vol 1: Development of Summary Residue Database for Dietary Exposure Assessment. Washington, DC:Technical Assessment Systems, Inc. 1993.

29. Macintosh DL, Spengler JD, Ozkaynak H, Tsai L-H, Ryan PB. Dietary exposures to selected metals and pesticides. Environ Health Perspect 104:202-209 (1996).

30. Stellman SD, Djordjevic M, Muscat J, Citron M, White A, Kemeny M, Busch E. Adipose and serum levels of organochlorinated pesticide and PCB residues in Long Island women: association with age and body mass [abstract]. Am J Epidemiol:S21 (1997).

31. Jensen AA. Background levels in humans. In: Halogenated Biphenyls, Terphenyls, Naphthalenes, Dibenzodioxins and Related Products (Kimbrough RD, Jensen AA, eds). Amsterdam:Elsevier, 1989;345-380.

32. Akins JR, Waldrep K. Bernert JT Jr. The estimation of total serum lipids by a completely enzymatic 'summation' method. Clin Chem Acta 184:219-226 (1989).

33. Phillips DL, Pirkle JL, Burse VW, Bernert JT Jr, Henderson LO, Needham LL. Chlorinated hydrocarbon levels in human serum: effects of fasting and feeding. Arch Environ Contam Toxicol 18:495-500 (1989).
34. Schmitt CJ, Zajicek JL, Peterman PH. National contaminant biomonitoring program: residues of organochlorine chemicals in U.S. freshwater fish, 1976-1984. Arch Environ Contam Toxicol 19:748-781 (1990).

35. Hovinga ME, Sowers M, Humphrey HEB. Environmental exposure and lifestyle predictors of lead, cadmium PCB, and DDT levels in Great Lakes fish eaters. Arch Environ Health 48:98-104 (1993).

36. van't Veer $P$, Lobbezoo IE, Martin-Moreno JM, Guallar E, Gomez-Aracena J, Kardinaal AFM Kohlmeier L, Martin BC, Strain JJ, Thamm M, et al. DDT (dicophane) and postmenopausal breast cancer in Europe: case-control study. Br Med J 315:81-85 (1997).

37. Rogan WJ, Gladen BC, McKinney JD, Carreras N, Hardy P, Thullen J, Tingelstad J, Tully M. Polychlorinated biphenyls (PCBs) and dichlorodiphenyl dichloroethene (DDE) in human milk: effects of maternal factors and previous lactation. Am J Public Health 76:172-177 (1986).

38. Stehr-Green PA, Farrar JA, Burse VW, Royce WG Wohlleb JC. A survey of measured levels and dietary sources of selected organochlorine pesticide residues and metabolites in human sera from a rural population. Am J Public Health 78:828-830 (1988).

39. DeVoto E, Kohlmeier L, Heeschen W. Some dietary predictors of plasma organochlorine concentrations in an elderly German population. Arch Environ Health 53:147-155 (1998)

40. Kreiss K. Studies on populations exposed to polychlorinated biphenyls. Environ Health Perspect 60:193-199 (1985).

41. Coulston F. Reconsideration of the dilemma of DDT for the establishment of an acceptable daily intake. Regul Toxicol Pharmacol 5:332-383 (1985).

42. Gunderson EL. FDA Total Diet Study, July 1986-April 1991, dietary intakes of pesticides, selected elements, and other chemicals. J Assoc Off Agric Chem Int 78:910-921 (1995).

43. Cullen AC, Vorhees DJ, Altshul LM. Influence of harbor contamination on the level and composition of polychlorinated biphenyls in produce in greater New Bedford, Massachusetts. Environ Sci Techno 30:1581-1588 (1996).

44. MacIntosh DL, Williams PL, Hunter DJ, Morris SC Willett WC, Rimm EB. Evaluation of a food frequency questionnaire-food composition approach for estimating dietary intake of inorganic arsenic and methylmercury. Cancer Epidemiol Biomark Prev 6:1043-1050 (1997).

45. Romeiu I, Stampfer MJ, Stryker WS, Hernandez M, Kaplan L, Sober A, Rosner B, Willett WC. Food predictors of plasma beta-carotene and alpha-tocopherol: validation of a food frequency questionnaire. Am J Epidemiol 131:864-876 (1990).

46. London SJ, Sacks FM, Caesar J, Stampfer MJ, Willett WC. Fatty acid composition of subcutaneous adipose tissue and diet in postmenopausal US women. Am J Clin Nutr 54:340-345 (1991).

47. Duarte-Davidson R, Jones KC. Polychlorinated biphenyls (PCBs) in the UK population: estimated intake, exposure and body burden. Sci Total Environ 151:131-152 (1994).

48. Mes J, Newsome WH, Conacher HBS. Levels of specific polychlorinated biphenyl congeners in fatty foods from five Canadian cities between 1986 and 1988. Food Addit Contam 8:351-361 (1991). 